\title{
Ongoing thrombosis assessed by optical coherence tomography
}

\section{Trombosis en curso evaluada mediante tomografía de coherencia óptica}

\author{
Santiago J. Camacho-Freire*, Antonio E. Gómez-Menchero, Jessica Roa-Garrido, Marcos López-Rojas, \\ Javier León-Jiménez, Rosa Cardenal-Piris and José F. Díaz-Fernández \\ Department of Cardiology, Hospital Universitario Juan Ramón Jiménez. Huelva, Spain
}

Two interesting cases of coronary percutaneous intervention $(\mathrm{PCl})$ are presented, describing the very early phase of vascular thrombosis after in-stent restenosis (ISR) treatment and resorbable scaffold implantation using optical coherence tomography (OCT) imaging, which required a change of therapeutic attitude.

The first patient is a 51-year-old woman with hypertension, dyslipidemia and type 2 diabetes, and a history of non-ST-elevation myocardial infarction one year prior, with anterior descending artery (ADA) revascularization by implantation of two overlapping anfilimus-eluting stents (Cre8 $3^{\star} 25$ and $2.75^{*} 12 \mathrm{~mm}$ ). An angiographic examination performed one year later due to progressive angina revealed severe focal ISR (Fig. 1A) in the overlapping area, with a stratified pattern, although without neo-atherosclerosis on OCT imaging (Fig. 1B), on which $\mathrm{PCl}$ was performed. Second anti-aggregant loading-dose (prasugrel $60 \mathrm{mg}$ ) was administered. After predilation with cutting balloon (Angiosculpt $3 \times 10 \mathrm{~mm}$ ) and since a good angiographic result was obtained, performing drug-coated balloon (DCB) angioplasty was decided (Sequent Please $3 \times 20 \mathrm{~mm}$ at $14 \mathrm{~atm}$ for $30 \mathrm{sec}$ ). Good angiographic result was verified and the OCT image showed a sieving of "cottony" aspect that corresponded to an amalgam of thrombotic content with remnants of neo-intima dissected after the $\mathrm{PCl}$, although with good luminal area (Fig. 1C). The procedure was considered terminated, but at 10 minutes, the patient developed chest pain and anterior ST-segment elevation. Angiography showed hyperacute thrombosis of the DCB-treated ISR (Fig. 1D). Balloon angioplasty was then performed with anti-Ilb/llla intracoronary administration and subsequent perfusion with good angiographic result (Fig. 1E). Re-interrogating the patient, she referred therapeutic noncompliance, which explained the complication. She had a good clinical evolution and on control angiography at one year, the good result was maintained (Fig. 1F).

The second patient is a 54-year-old male with a history of hypertension, segmental alterations in lateral and inferior aspects and clinical signs and symptoms of progressive angina. He was on treatment with acetylsalicylic acid $100 \mathrm{mg}$ and clopidogrel $75 \mathrm{mg}$ daily. The angiogram showed a severe calcified lesion on the diagonal branch (Fig. 2A), which was verified by OCT, with $\mathrm{PCl}$ being decided. Predilation was carried out with conventional and non-compliant (NC) balloon $(2.5 \times 20 \mathrm{~mm})$ and novolimus-releasing resorbable

\section{Correspondence:}

*Santiago J. Camacho-Freire

Secretaria de Hemodinámica

Hospital Universitario Juan Ramón Jiménez

Ronda Norte, s/n

Date of reception: 21-09-2018

Date of acceptance: 22-10-2018

E-mail: navallana@ hotmail.com

DOI: 10.24875/ACME.M19000016
Available online: 09-08-2019 Arch Cardiol Mex (Eng). 2019;89(1):86-89 www.archivoscardiologia.com 2604-7063 @ 2018 Instituto Nacional de Cardiología Ignacio Chávez. Published by Permanyer México. This is an open access article under the CC BY-NC-ND license (http://creativecommons.org/licenses/by-nc-nd/4.0/). 


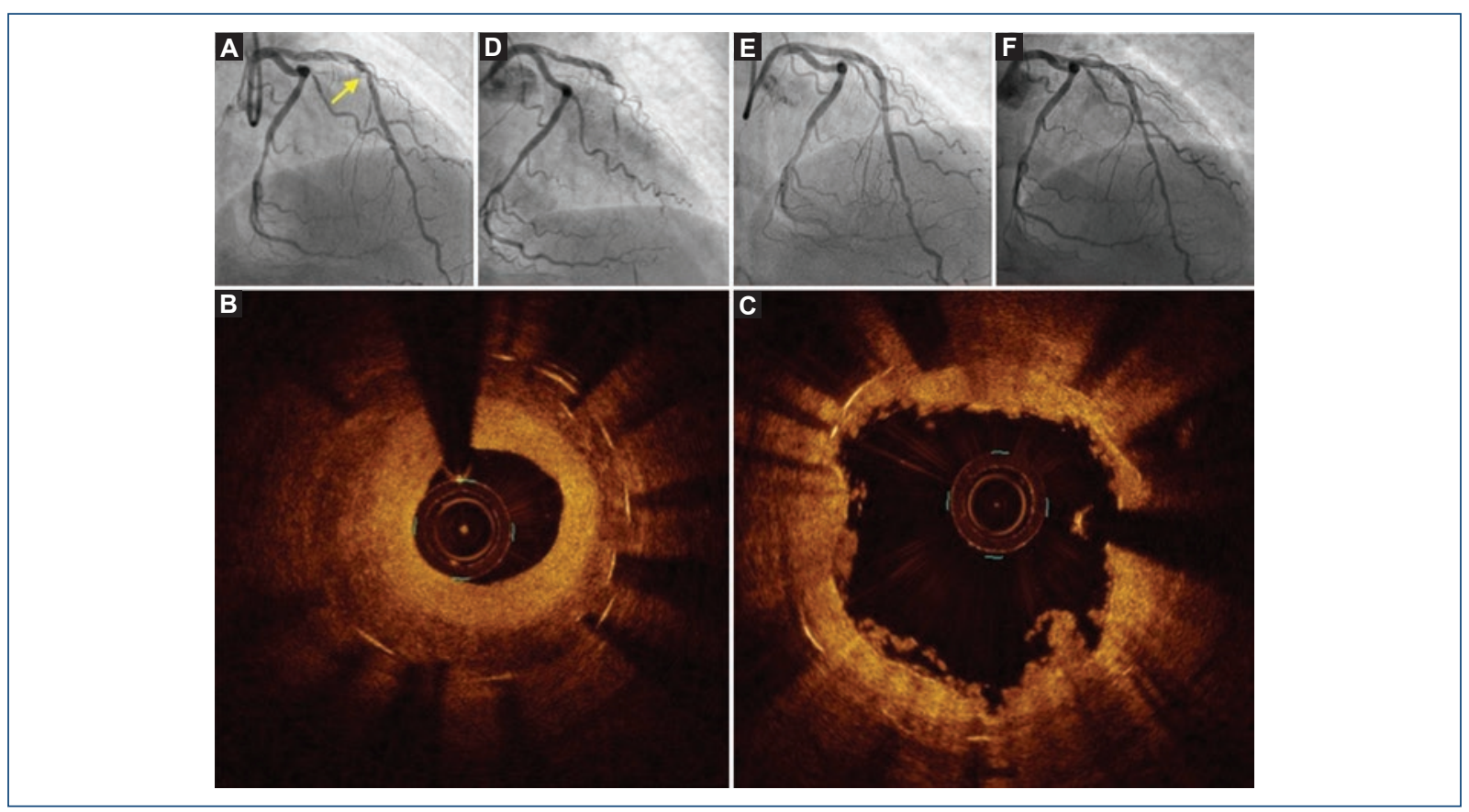

Figure 1. A: angiographic image of a severe focal in-stent restenosis (yellow arrow) in the mid-anterior descending artery (ADA). B: optical coherence tomography (OCT) image of an in-stent restenosis stratified pattern at the point of overlap. C: OCT image after balloon predilation and drug-coated balloon (DCB) angioplasty with defragmented residual intima and some thrombus particles. D: angiographic image of mid-ADA stent thrombosis after DCB angioplasty. E and F: angiographic final result and at one-year follow-up.

scaffold (Desolve $2.5 \times 28 \mathrm{~mm}$ ) was implanted, with NC balloon postdilation concluding with good angiographic result (Fig. 2B). OCT imaging showed malapposition at the proximal level and images of thrombotic appearance covering the entire scaffold (Figs. $2 \mathrm{C}$ and 2D). At that moment, anti-Ilb-Illa intracoronary administration and perfusion, and proximal segment NC balloon-postdilation was decided. New OCT acquisition was made at 10 minutes, which showed a marked decrease of the thrombotic content and good apposition of the previously-implanted scaffold (Fig. 2E). The patient had good evolution, both clinically and on angiographic examination.

\section{Discussion}

Intracoronary imaging techniques can be an invaluable aid as a complement for diagnosis and/or treatment of patients undergoing PCl. Although intracoronary ultrasound has been available for more than two decades in our hemodynamics laboratories and is widely used, scientific evidence supporting its use during percutaneous intervention did not arrive until years later ${ }^{1}$. OCT provides, partly owing to its great resolution, a series of findings with clinical implications and prognostic value that still need to be defined in large randomized studies.

In addition to the valuable information it provides for the diagnosis of de novo lesions, the development of OCT has allowed to define ISR patterns and new concepts such as neo-atherosclerosis ${ }^{2,3}$, among others.

Different studies have demonstrated the usefulness of OCT in the immediate post-stent implantation period, which is able to identify processes directly related to stent thrombosis and restenosis ${ }^{3,4}$. Underexpansion $(<90 \%$ of the vessel mean luminal area), malapposition (> $260 \mu \mathrm{m}$ from the strut to the vascular wall), significant border dissection (> $200 \mu \mathrm{m}$ flap and/or $>180^{\circ}$ of vessel circumference, especially in the stent distal extreme), plate prolapse or uncovered plate and minimal luminal area after stent implantation $\left(<4.5 \mathrm{~mm}^{2}\right)$, have been defined as factors associated with events ${ }^{3,4}$.

However, and although the OCT-detected complication images certainly seem to have importance, there is still some controversy on whether systematic use of OCT as a guide in interventions might be associated with better clinical results ${ }^{3-5}$. 


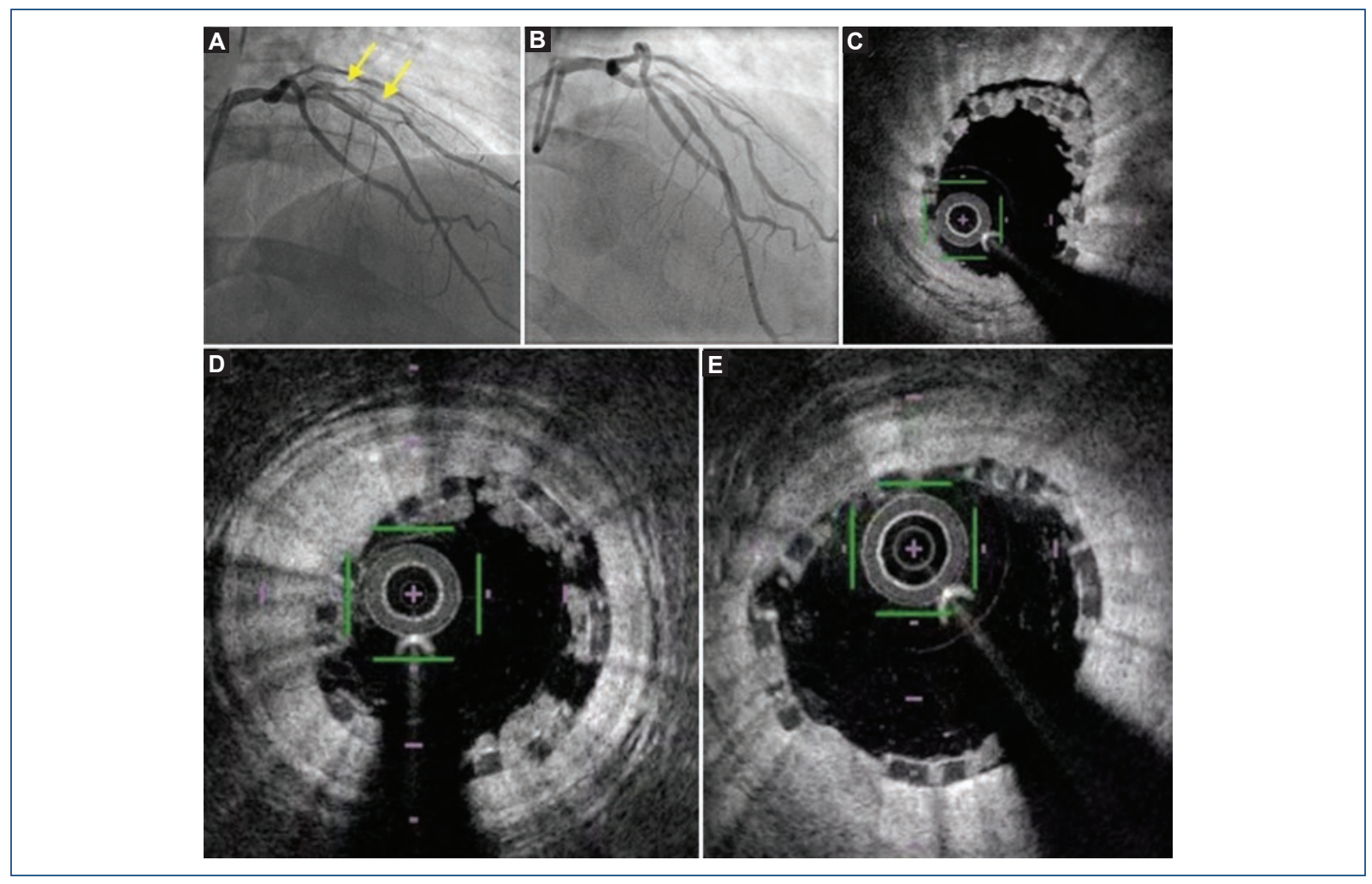

Figure 2. Coronary angiography showing A: a severe, calcified lesion (yellow arrows) on the diagonal branch. B: coronary angiography after resorbable scaffold implantation. C: optical coherence tomography (OCT) images of malapposition in proximal segment. D: thrombotic images covering the entire scaffold. E: OCT image showing a significant reduction of thrombotic load and good apposition of the previously implanted scaffold.

Stent thrombosis is an uncommon but serious complication. Although the information on thrombosis initial phases by OCT is scarce, a slow flow pattern has been described that could represent a risk factor for stent thrombosis ${ }^{6}$. The presented cases are a clear example of how the recognition of these OCT patterns can, per se, guide patient treatment.

The first case illustrates an arterial thrombosis after treatment of an ISR with DCB. This phenomenon can be explained, in part, by poor treatment adherence, although it remains an exceptional complication, especially without major neo-intimal dissection.

The second case shows the more pro-thrombotic tendency shown by current scaffolds versus second-generation metal stents, especially in small vessels and long lesions. OCT imaging was essential to prevent the evolution of an ongoing hyperacute thrombosis, in addition to revealing proximal malapposition, which could have determined an increased risk of thrombosis and/ or restenosis in the future.

The experience of the first case, which evolved into thrombosis, allowed us knowing that the represented image may correspond to an ongoing thrombosis. The characterization of this OCT pattern in the immediate post-implant period must be associated with an increase in antiaggregation/anticoagulation.

\section{Conflicts of interest}

The authors declare not having any conflicts of interest or having received any funding.

\section{Ethical disclosures}

Protection of people and animals The authors declare that no experiments have been conducted on humans or animals for this research.

Confidentiality of data The authors declare having followed the protocols of their work center on the publication of patient data.

Right to privacy and informed consent The authors declare that no patient data appear in this article. 


\section{References}

1. Ahn JM, Kang SJ, Yoon SH, Park HW, Kang SM, Lee JY, et al. Meta-analysis of outcomes after intravascular ultrasound-guided versus angiography-guided drug-eluting stent implantation in 26,503 patients enrolled in three randomized trials and 14 observational studies. Am $J$ Cardiol. 2014;113(8):1338-47.

2. Nicol $P$, Xhepa $E$, Bozhko D, Joner M. Neoatherosclerosis: from basic principles to intravascular imaging. Minerva Cardioangiol. 2018;66(3):292-300.

3. Räber L, Mintz GS, Koskinas KC, Johnson TW, Holm NR, Onuma Y, et al. Clinical use of intracoronary imaging. Part 1: guidance and optimization of coronary interventions. An expert consensus document of the
European Association of Percutaneous Cardiovascular Interventions Eurolntervention. 2018;14(6):656-77.

4. Meneveau N, Souteyrand G, Motreff P, Caussin C, Amabile N, Ohlmann $\mathrm{P}$, et al. Optical coherence tomography to optimize results of percutaneous coronary intervention in patients with non-ST-elevation acute coronary syndrome results of the multicenter, randomized DOCTORS study. Circulation. 2016;134:906-17.

5. Ali ZA, Maehara A, Généreux P, Shlofmitz RA, Fabbiocchi F, Nazif TM, et al. Optical coherence tomography compared with intravascular ultrasound and with angiography to guide coronary stent implantation (ILUMIEN III: OPTIMIZE PCI): a randomised controlled trial. Lancet. 2016;388:2618-28.

6. Cuesta J, Rivero F, Alfonso F. Ongoing stent thrombosis: Optical coherence tomography findings. Rev Esp Cardiol (Engl Ed). 2015;68(11):1024. 